\title{
The Type-Token Distinction and Four Problems with Propertarian IP Justifications
}

\section{Wojciech Gamrot ${ }^{1}$ (D)}

Received: 5 January 2021 / Accepted: 12 May 2021 / Published online: 21 May 2021

(c) The Author(s) 2021

\begin{abstract}
Propertarian justifications of intellectual property postulate the appropriation of various entities, often called patterns, designs, or technologies. These must be immaterial and should not be confused with material structures that embody them. Hence two classes of objects are distinguished. It is convenient to refer to them as types and tokens. The type must involve a condition defining which material structures should be considered its tokens. For an IP regime to be economically meaningful one must necessarily appropriate types in a way which restricts access to wide classes of similar, non-identical material structures. Therefore, type conditions must be general. They must define, with a margin of tolerance, only certain aspects of the structure, leaving others unspecified. Consequently, the relationship between such types and tokens is of many-to-many variety. The recognition of these facts leads to four problems in justifying intellectual property on propertarian grounds. The first problem is to demonstrate possession of the type in the pre-legal situation. The second one is to explain, why boundaries of an appropriated type should be placed in a particular location. The third problem is to avoid claim deadlocks resulting from conflicts of rights generated by separate overlapping types. The fourth problem is to justify why ownership of the type should entail the control over other separate entities - that is tokens. In the propertarian framework grounded in the pre-legal state of nature, satisfactory solutions do not seem to have been proposed for any of these four problems.
\end{abstract}

Keywords Type $\cdot$ Token $\cdot$ Relation $\cdot$ Intellectual property $\cdot$ Patent $\cdot$ Copyright

Wojciech Gamrot

wojciech.gamrot@ue.katowice.pl

1 Department of Statistics, Econometrics and Mathematics, University of Economics in Katowice,

1 Maja 50, 40-287 Katowice, Poland 


\section{Introduction}

According to Drahos (1996: 210-219) intellectual property (IP) justifications may be divided into two categories: propertarian and instrumentalist. Propertarian theories hold that IP rights are pre-legal, pre-contractual moral constraints, sharing the ethical foundations with property rights in material objects. According to instrumentalist theories IP is derived from other desirable social goals, such as maximization of utility, disclosure of innovations or encouragement of technical progress. In this investigation the credibility of propertarian justifications is assessed from a philosophical and ethical perspective. The focus is mainly placed on justification of patent systems, but the study is relevant to any IP rights that one might attempt to vindicate under the deontological, propertarian framework. The analysis of economic or sociological aspects of IP, as well as existing legal regulations and their statutory interpretations exceeds the scope of this work and is not pursued.

Nobody is prosecuted for merely thinking about innovations, stories or melodies that someone else came up with earlier. IP rights boil down to the control of material property (Hughes 1988; Breakey 2010) and always involve material structures, that is gatherings of matter formed in a particular way. They are violated by actions affecting matter, such as arranging it into a prohibited configuration, selling the resulting material structure, offering services of that structure, or benefiting from it in other ways. These actions are forbidden despite the fact, that the perpetrator may be a rightful owner of all involved material components. In fact, those who make replicas of artworks usually use their own paints, and canvasses. Those who copy films and music usually record it on their own media and play it using their own home theater hardware. Those who reproduce gadgets tend to use their own 3D printers and their own filaments. Most producers of derivative works also construct them from legitimately owned material ingredients. The prohibition cannot be explained by the ownership of material objects as their boundaries are not violated by producing copies. In order to represent interests of those who want prohibition another entity must be introduced that could be said to be trespassed on by reproduction. Its nature must enable identification of prohibited material structures. It is convenient to interpret it as a type (Moore 1997; Dodd 2000, 2007; Shiffrin 2007; Biron 2010; Wilson 2010). The type involves a condition which must be satisfied if the material structure is to be considered an embodiment of that type. The condition describes selection and required properties of material items as well as connections among them. The material structure that conforms to the condition is called a token. The ordering of matter may be spatial (gears and levers in a clock, paint on a canvas etc.) or spatiotemporal (motion of particles in a chemical reaction, moves of a dancer, sequence of pixel color changes in a LCD screen etc.). This universal designation enables joint analysis of various entities which are subject to IP regulations. In particular, "practical applications of ideas" regulated by patent laws are various types, which are embodied in gadgets, machines, materials, and industrial processes. Likewise, "expressions of ideas" subject to copyright regulations are types, which 
are embodied in films, poems, melodies, sculptures, computer games, and theatrical plays. The subject matter of other IP branches such as trade marks, integrated circuit topologies, boat hull designs and plant varieties also consists of types embodied in diverse material structures.

The propertarian justification of IP postulates that types may be unilaterally appropriated in a pre-legal situation without any prior contract binding parties and that their ownership entails the right to control their tokens. According to Moore (2003) this in particular includes the right to prohibit their unauthorized production, sales and use. Such a meaning of IP will be assumed in the following discussion. Authors who maintain that IP regulation could be justified by an appeal to natural rights, thereby referring to the propertarian theory, include among others Hughes (1988), Yen (1990), Gordon (1993), Zemer (2006), Moore (2012) and Mossoff (2012). In what follows four separate general objections to the propertarian IP justification are presented. The first three of them might be considered an answer to the question posed by Shaffer (2013:18):

Are the origins of IP interests to be found in the informal processes by which men and women accord to each other a respect for the inviolability of their lives - along with claims to external resources (e.g., land, food, water, etc.) necessary to sustain their lives? Or, are they to be established by formally enacted rules generated by political systems?

The fourth objection is related to the structure of the propertarian theory and capitalizes on the consequences of type-token distinction.

\section{The Possession Problem}

The first flaw in the propertarian IP theory stems from the important difference between material and immaterial objects. Those which are material are easily observable. Taking them into possession may be demonstrated and documented. Being excludable, they may be kept in a secure location, locked, fenced or otherwise marked as property and guarded. However immaterial types cannot be treated in this way. This is summed up by the words of Błaszczyk (2020):

Since abstract objects do not have a physical manifestation (they may be embodied only into their exemplars), it is impossible to establish a real possession over them and, consequently, demonstrate it in an objectively perceivable manner. In other words, the only way to appropriate a work or an invention is through a declaration. However, there is no reliable and undisputable manner of fixing anteriority to intangibles in the state of nature (this is important since only unowned goods may be appropriated), because communicating an idea to the public automatically frees it from one's exclusive control. This would lead to the unavoidable and unsolvable disputes over precedence of acquisition of abstract objects, thus depriving a social order of the supposed harmony of propertarian relations, for who is to judge whether an individual actually conceived a given conception before others. Mankind knows no fair technique 
of reading people's minds. Thus, IP needs decreed and constrained fiduciary relations, ergo may exist only outside the state of nature, which lacks a general authority that could constitute and execute titles in intangibles.

The functioning of IP requires certain actions to be performed. Chronological order of origination must be tracked. A directory of property titles must be maintained. Prohibition must be dictated to the general population. Restrictions on instantiation must be monitored and enforced. All these tasks cannot be fulfilled without political institutions which are not available and cannot be counted on in the pre-legal, precontractual state of nature. This is sufficient to declare that propertarian justification for IP has failed. In the following sections it is demonstrated that other essential functions of IP system cannot be performed without political institutions either.

\section{The Individuation Problem}

The condition that constitutes the type may be specified more or less strictly, resulting in wider or narrower classes of prohibited material structures. As an extreme, one might consider exact types that characterize precisely all the aspects and all the details of material structure. These types may be thought of as perfect exhaustive recipes that enable reproduction of tokens down to the tiniest microscopic detail. All tokens of such a type would consist of identical and identically ordered material components. They would be perfect copies of each other. The extensive condition of such a type would be expressed as a conjunction of equations, rather than inequalities. As an opposite extreme one might also consider the least-specific, most-general hypothetical super-type $\Omega$ whose condition is fulfilled by all time-spatial configurations of matter. Between these two extremes lies a continuous logical space of possible type conditions of varying generality and complexity.

From the economic point of view the ownership of individual exact types is pointless. Their conditions would have to determine the arrangement of matter down to the tiniest detail. Even documenting them would in most cases require a great effort. Various imperfections of material ingredients and limited precision of physical equipment used for production would most likely result in the assembly of material structures that deviate from the exact specification anyway. More importantly, replicas produced by competitors would not satisfy type's exact condition either, so there would be no propertarian grounds for accusing them of IP infringement. In fact, minor distortions could be introduced deliberately in order to legally circumvent prohibition, while preserving advantages of the structure. This would make IP rights useless. The same holds for types which are not exact, but specify exactly only some aspects of the structure. Such a situation is illustrated by the Example 1.

Example 1 Let the type $T$ describe the use of an advantageous combination of two substances-say $M$ and $N$-whose shares respectively equal $f=0.6$ and $1-f=0.4$. Hence the structure is described by a single numeric parameter: the proportion $f$. For simplicity let us assume that $M$ and $N$ have no equivalents and cannot be replaced with other substances. The condition of this type does not specify the 
spatial distribution of particles. Hence $T$ is not exact. However in order to produce its tokens one has to guarantee that they contain exactly 4 particles of $N$ for every 6 particles of $M$. This would require counting individual molecules - a technically challenging task that may be impossible to implement at industrial scale. And even if this objective is achieved, chemical reactions and physical processes such as leaking or venting may quickly distort proportions of ingredients so that the mix ceases to constitute the token of $T$. Meanwhile it is not possible to prevent competitors from producing mixes of $M$ and $N$ characterized by the proportion $f=0.5999$ that remains beneficial but is not forbidden as it does not conform to $T$ 's precise condition. Therefore it is pointless to own $T$.

The example might appear trivial, with only one numeric characteristic. Entities covered by contemporary patents and copyright tend to be more sophisticated. However adding complexity to the type condition would not eliminate the stated problem. The mix of $R$ substances might be described by a vector of $R-1$ components describing their ratios or shares in the mix. Various geometric structures, machines, industrial processes, integrated circuit topologies, or digital photos are also easily described by longer or shorter sequences of numbers. With adequate effort mostif not all-material structures might be characterized this way. ${ }^{1}$ When some of the numbers are specified exactly by type's condition, the same problem may be expected to appear. Hence the mixing example serves as a useful model that captures an important aspect of more complex situations.

For an IP regime to make economic sense one has to take ownership of types in a manner which restricts access to wide classes of similar, non-identical material structures. Hence type conditions must be general. They must specify wide value ranges for characteristics of the structure, while some aspects may remain undetermined. As a consequence, every material structure will simultaneously satisfy conditions of numerous distinct general types. This is illustrated by the Example 2.

Example 2 A material structure $\mathrm{S}_{1}$ is a mix of two substances $M$ and $N$, characterized by a proportion $f=0.6$. The mix embodies various general types. In particular it is a token of type $T_{1}$, that corresponds to the proportion of these ingredients belonging to a range [0.51, 0.64], the type $T_{2}$ with an associated range [0.54, 0.67] and the type $T_{3}$ with an associated range $[0.48,0.68]$. At the same time, the type $T_{1}$ is embodied in various different tokens, that include among others the material structure $S_{1}$, but also structures $S_{2}$, and $S_{3}$, respectively characterized by proportions 0.62 and 0.56 , as shown in Fig. 1 .

Types and tokens are involved in a many-to-many relationship. Their situation is analogous to associations between sellers and buyers, between transmitters and receivers, as well as between teachers and students. Each entity of one kind (sellers, transmitters, teachers) may be related to many entities of the second kind (buyers,

\footnotetext{
1 A close affinity between IP objects and numbers is also discussed by Moglen (1999).
} 


\section{T3}

T2

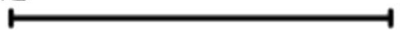

T1

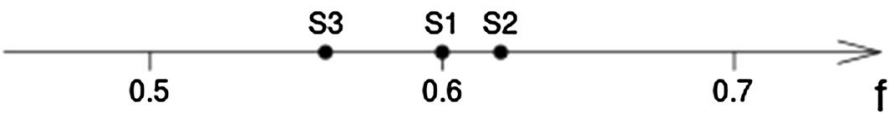

Fig. 1 Type-token relations in the Example 2

receivers, students) and vice-versa. Analogically, a general type may be embodied in numerous different tokens. A token may at the same time embody numerous different general types.

It might be intuitively tempting to declare, that anyone who is the first to come up with any type should be granted the ownership of that type. However, if this is admitted without restrictions, then the first individual who appropriates the universal super-type $\Omega$ becomes able to claim the right to control any existing material structure. A similar effect may be achieved by declaring ownership of other very general types, that cover broad classes of inventions, science-fiction films, criminal novels, romantic poems, paintings, melodies, and so on. This is illustrated by Examples 3 and 4.

Example 3 Let Alice discover that the mix of substances $M$ and $N$ described by the proportion $f=0.6$ has desirable properties. It may be beneficial for her to appropriate a type that covers all proportions $f \in[0.5,0.7]$. She might consider more beneficial to own the type that corresponds to $f \in[0.5,0.8]$ or to $f \in[0,1]$. And it is probably even more beneficial to appropriate all mixes that contain $M, N$ and some other substances. Nevertheless, she might still prefer to appropriate the type that covers any mix of any substances.

Example 4 Let Alice write a book that contains a sequence of $X$ words. She might consider appropriation of a type $T_{X}$ that covers all books that contain exactly the same combination of words. However she would most likely choose to own the type 
$T_{Y}$ that covers all books that contain any subsequence of $Y$ words from her book for $Y<X$. She would rather prefer lower than higher values of $Y$, with the most desirable option being $Y=1$, that entails prohibition of any books that repeat any word of the initial sequence.

Without restricting the scopes of ownable types, the IP regime turns into an absurd contest on who is the first to appropriate the right to control the whole universe. Hence, while types must be general in order to be economically meaningful, they also cannot be too general in order to avoid a glaring absurdity. Any viable IP system must be equipped with some restriction on kinds of types that could be appropriated. Propertarian IP theories must account for that choice. They must explain why a given type condition should be preferred over others, and in particular over that of the exact type and that of the universal super-type $\Omega$. This is known as the individuation problem (Attas 2008).

Unfortunately for IP-advocates types have no natural boundaries. They have no intrinsic properties that could suggest a legitimate range of configurations to be prohibited. An infinite logical space of possible conditions is a continuum. ${ }^{2}$ Conflicting subjective views on their formulation cannot be reconciled by consulting any objective empirical reality. There is no guarantee that two isolated groups of experts will set them in the same way. In fact exactly the opposite should be expected, and there is no objective way to prove that the verdict of one group is better than that of the other.

It is certainly possible to erect political institutions that try to define boundaries of owned areas in a logical space of possible conditions. Expert committees may be established to debate on the meaning of general clauses such as novelty, non-obviousness, originality or similitude (Gordon 2003) in every particular case. Following the advice of Yen (1990) they may try to identify the part of any given type designed by its originator as opposed to the contribution of a broader society. Convoluted procedures like the Abstraction-Filtration-Comparison Test (Risch 2019) may be devised in order to add credibility to their rulings. Appeal courts may be set up to re-consider initial judgments if they are contested. However, as noted by Błaszczyk (2020), the existence of such institutions cannot be presumed in the state of nature. They cannot be summoned to the rescue in the pre-legal, pre-institutional and precontractual context of the propertarian IP justification. Without them, no one in the state of nature would know the scope of prohibition. IP would be rendered an exercise in gambling, violating the nullum crimen sine lege principle. Hence it cannot be justified on propertarian grounds.

\footnotetext{
${ }^{2}$ Even those principles that guide appropriation of physical object in such difficult cases as taking ownership of land are not applicable to them. One may be able to identify the territory that was purposefully transformed by human labor and accordingly set up the boundaries of land property (Becker 1977:2627). However this is not possible for intangible types that do not interact with matter. The knowledge of tokens might at best enable unequivocal determination of exact types, but it is certainly insufficient to identify boundaries of general ones under the propertarian framework.
} 


\section{The Overlap Problem}

For the sake of argument let us suppose that the first two challenges may be successfully addressed. Hence we generously assume that by some miracle a mechanism for identification of type boundaries, followed by registration and enforcement of property titles, may be justified in the state of nature.

Those who advance the propertarian justification of IP must then face another problem. After the type-say $T$-is taken into ownership, newcomers might challenge the IP right of its owner by appropriating other, different types-say $U, V$, $W$ - that happen to cover some of material structures already covered by $T$. Each newcomer might counter the IP right of $T$ 's owner with an opposite IP right in $U, V$ or $W$. Beneficial gatherings of matter would be subject to a growing number of newcomers' conflicting claims resulting in a deadlock and forcing the society to abolish IP. This is illustrated by the Example 5 .

Example 5 Let Alice appropriate the type $T_{1}$, which permits her to prohibit any mixes of $M$ and $N$ characterized by the proportion $f \in[0.51,0.64]$. In particular, she might prohibit the construction of structure $\mathrm{S}_{1}$ that corresponds to $f=0.6$. However, Bob may subsequently take ownership of the type $T_{4}$ that covers all mixes with the proportion $f \in[0.57,0.69]$, and challenge Alice's right to the structure $S_{1}$. If he also appropriates the type $T_{5}$ that corresponds to $f \in[0.49,0.58]$ then he may prevent Alice from producing any tokens of her type $T_{1}$. In order to continue production, Alice has to negotiate with Bob, and with any newcomers who appropriate some convenient new types that are not yet owned.

The appropriation of overlapping types by newcomers cannot be prohibited on propertarian grounds. They are separate, distinct entities, which is easily demonstrated by pointing out that collections of material structures they cover are not the same. ${ }^{3}$ Moreover, it cannot be demanded on propertarian grounds that newcomers' types should be originated "independently". The types $T, U, V, W, \ldots$ are separate entities, so the ownership of $T$ does not imply the right to prohibit appropriation ${ }^{4}$ of $U, V, W, \ldots$ Besides, in a pre-legal state of nature there is also no political institution that could set any standards of what counts as an independent invention and verify compliance with any such requirements. Consequently, there is no propertarian basis for discrimination against newcomers, as taking ownership of an unowned object does not violate property rights in other already owned separate objects. A coherent

\footnotetext{
3 An objection that types which are "similar enough" are in fact equivalent is dismissed by pointing out that equivalence relation is transitive. Hence any type $U$ might be declared equivalent to $T$, by finding a convenient sequence of types $T^{(1)}, T^{(2)} \ldots, T^{(k)}$, where $T^{(\mathrm{i})}$ and $T^{(\mathrm{i}-1)}$ are similar enough to be considered the same for $i=2, \ldots, k$, while $T^{(1)}=T$ and $T^{(\mathrm{k})}=U$. That would be absurd.

4 Most innovations and artistic activities depend on someone's earlier work. The invention of microprocessor depends on earlier inventions of integrated circuits, transistors, and semiconductors. The writing of books depends on the invention of alphabet, writing instruments and on works of art that shaped author's skills. If independence was required among separate types, then most types could not be owned, and IP would be pointless.
} 
propertarian must admit that everyone has the right to block others by appropriating new types. The IP regime based on the propertarian justification cannot avoid a deadlock of claims, and it must collapse. ${ }^{5}$

\section{The Distinction Problem}

Without downplaying the arguments stated in preceding sections, let us consider another, more fundamental issue. Being separate entities, types and tokens may have different status with respect to property rights and underlying moral principles. Eventual control over them needs to be separately justified. Hence the following question may be raised:

Why should ownership of one entity - the immaterial type - entail the right to control other separate entities - that is material tokens?

This question may perhaps be trivial to answer in the context of instrumentalist theories, but for the propertarian one it deserves closer attention. In what follows, three possible answers are investigated.

One possible intuitive response to the stated challenge could be, that the type is somehow automatically included, embedded or present in all its tokens so that it constitutes an integral part of them. On this view the copying would be tantamount to "using" the type. However such an answer is a blatant category error. An immaterial entity has no volume, dimensions, or location, and it is not subject to spatial relations. It cannot be "in" anything material, just as the envy is not in the newest Bugatti, the exchange value is not in the bank note and as Einstein's $E=m c^{2}$ equation is not in annihilating elementary particles. Such statements might perhaps be accepted in poetry as loose lyrical metaphors, but they must be rejected in precise scientific discussion.

Another, more sophisticated answer could be to claim, that the considered type is somehow necessary for the production of tokens. However, numerous empirical observations evidence that the structure may be brought to existence without conceiving any type that would cover it. These include various innovations that spontaneously appear in the nature without any human involvement, such as hunting net, sucking pump, hook-and-loop fasteners, sonar, anesthetics and antibiotics. There is also no law of physics that would rule out the possibility that bright and dark grains of sand on the beach are arranged by the wind in a pattern that corresponds to earlier or later work of some painter, photographer or writer. An extremely low likelihood of such occurrence does not prove its impossibility. The material structure may also be produced and even distributed in large quantities by accident. This is illustrated by Examples 6 and 7 .

\footnotetext{
5 This reasoning should not be confused with a similar argument of Gamrot (2021), as it does not require any additional assumptions on type identity.
} 
Example 6 Let the beneficial mix of substances $M$ and $N$ described by a proportion $f=0.6$ be known and applied industrially — say as an anti-dandruff shampoo associated with a patented type $T$ that corresponds to $f \in[0.55,0.65]$. Let some inexperienced worker in a shampoo factory misread the manual of the production equipment and by mistake unknowingly apply the proportion $f^{\prime}=0.4$ that happens to have an even more potent anti-dandruff effect. If the fact remains unnoticed, the new mix may be mass produced, widely distributed and appreciated by buyers without anyone being aware of any new types covering it.

Example 7 The surveillance camera may accidentally record and automatically broadcast a picture that possesses unique aesthetic qualities. The photo may then be printed and hanged in people's dining rooms and art galleries without anyone bothering to formulate any general type.

More importantly, the claim of type necessity immediately collapses as soon as non-exactness of types is admitted. The relation of these types to tokens is of manyto-many kind. The number of such types that may serve as a general recipe for a given material structure is infinite. Each of them may serve as a guidance for construction of the structure while others may remain unknown. It might always happen that the structure is built with yet another, different type in mind, without knowing the former. Applying this realization uniformly to all general types one must reject the notion that knowledge of any particular general type is necessary to build the structure. Another, different one would be equally suitable. This is illustrated by the Example 8.

Example 8 The beneficial mix of substances $M$ and $N$ characterized by the proportion $f=0.6$ may happen to be manufactured no matter if its producer wishes to embody the type $T_{1}, T_{2}$ or $T_{3}$ from the Example 2 .

While the knowledge of general types is undoubtedly a desirable condition and may greatly facilitate the assembly of tokens, it is untrue that any single one of them is indispensable for production. Hence the second answer to the stated challenge also fails.

The third possible response might refer to the concept of value. It might be claimed that the prohibition should be introduced in order to protect type's value. This answer also fails. As noted by Błaszczyk (2020), it is impossible to establish real possession over types, so they cannot be subject to transactions. Humans can perceive them, but cannot exclude others from arriving at the same type either by observation, or by their own intellectual effort. ${ }^{6}$ They cannot even surrender the knowledge of a type, as there is no reliable way of selectively erasing human memory. It is of course possible to inform others about types-freely or in exchange for

\footnotetext{
${ }^{6}$ Claims that sufficiently complex types cannot be independently arrived at, such as those of Himma (2008) or Rand (1986: 142) are shown to be groundless by pointing out that the allegedly impossible event has already happened once.
} 
payment—but this does not entail owning them, just as the fact that an astronomer informs others about location and characteristics of some distant galaxy in exchange for a payment does not imply that anyone owns that galaxy. Both acts simply involve the sale of services which are unrelated to the ownership of the object to which they refer. ${ }^{7}$ Without transferring possession of types, preferences for a type with respect to other goods cannot be demonstrated. Hence it is nonsensical to assign exchange values to types.

What remains, is a related complaint that actions of competitors reduce the demand for tokens produced and sold by type's owner which reduces their exchange value and profits from their sale (Cwik 2016). However this argument is also invalid as a justification for prohibition. Firstly, it is methodologically unsound. Individual preferences are ever-changing rank scale orderings with no obvious way of aggregating differing assessments into an objective numerical value measure. The exchange value is subjective. Its perceptions depend on time, space, circumstances, and the availability of tokens (cf. Wiśniewski 2020). They vary among individuals and may grow instead of falling when new tokens appear (Attas 2008). Moreover, tokens of non-exact general types do not have to be identical. They may possess various features that enable differentiation among them and be subject to diverse preferences. Hence the fact of producing or selling a token does not necessarily translate into the diminished demand for those offered by type owner. Indirect monetization of the type that is freely and widely embodied in tokens may be profitable, and perhaps more lucrative than exclusively selling lesser numbers of tokens under the monopoly privilege (Boldrin and Levine 2008: 23-24). Secondly, and more importantly, a consistently enforced protection of token exchange values leads to an absurd prohibition of any productive activity because the assembly of a substitute for anything might lessen the value of someone's existing stock of that thing, and reduce eventual profits from its sale ${ }^{8}$ (cf. Dominiak 2014). Hence the stated challenge still lacks a convincing answer. Without it, the propertarian IP justification appears to be an egregious case of non-sequitur.

\section{Conclusions}

What IP advocates want to control is a material entity. But what could eventually be trespassed on by copying must be immaterial. A single entity cannot be material and immaterial at the same time - that would violate the Aristotelian law of excluded middle. Hence it must be recognized that two entities of different nature are involved in the propertarian IP justification. The type-token distinction cannot be ignored or blurred. Its consequences must be recognized and accounted for.

\footnotetext{
7 The trade in IP that we observe in a contemporary world is not a trade in types, but merely the trade in IP rights, whose legitimization is yet to be established by the propertarian theory. To refer to such transactions in the justification of IP would be viciously circular, (cf. Bouckaert 1990; Wilson 2009).

8 This argument also works against the postulate of preserving type's value criticized above.
} 
The four problems described above are independent of each other. Each of them stems from the type-token distinction and appears to be sufficient to derail the propertarian IP theories. None of them seems to be solvable. Without addressing all of them, the propertarian justification of IP cannot be accepted, no matter if John Locke approved of IP or not.

Implications of the overlap problem deserve special attention. Several theorists see the ultimate justification of property rights in the need for eliminating conflicts over alternative uses of rivalrous resources. ${ }^{9}$ This principle is certainly applicable to material objects, which are all distinct from each other. ${ }^{10}$ Property rights in them can be uniquely determined, so that each material object may be exclusively controlled by a single owner. After the property rights are assigned, it is obvious who exercises authority over a given resource. The conflicts are thus resolved. The owners may be confident that their control over matter is stable and it will not be suddenly restricted by external events. In a stark contrast, the ownership of types does not eliminate conflicts over matter, but it breeds new ones. Firstly, conflicts emerge between owners of matter and owners of types. ${ }^{11}$ Their rights to control the same material objects inevitably collide. Secondly, conflicts also emerge between owners of various overlapping types, that cover the same material structures. As a result, neither the owner of matter, nor type owners can be certain of their right to produce tokens. Their control over matter becomes unstable. Newcomers with new overlapping types might appear at any time and prohibit everyone from the production. Therefore popertarian IP theories do not lead to the fulfillment of conflict-avoidance postulate, but to its perversion.

Open Access This article is licensed under a Creative Commons Attribution 4.0 International License, which permits use, sharing, adaptation, distribution and reproduction in any medium or format, as long as you give appropriate credit to the original author(s) and the source, provide a link to the Creative Commons licence, and indicate if changes were made. The images or other third party material in this article are included in the article's Creative Commons licence, unless indicated otherwise in a credit line to the material. If material is not included in the article's Creative Commons licence and your intended use is not permitted by statutory regulation or exceeds the permitted use, you will need to obtain permission directly from the copyright holder. To view a copy of this licence, visit http://creativecommons.org/ licenses/by/4.0/.

\section{References}

Attas D (2008) Lockean justifications of intellectual Property. In: Gosseries A, Strowel A, Marciano A (eds) Intellectual property and theories of justice. Palgrave Macmillan, New York, pp 29-56

Becker LC (1977) Property rights: philosophic foundations. Routledge \& Kegan Paul, London Bell TW (2007) Copyright as intellectual property privilege. Syracuse Law Rev 58:523-546

Biron L (2010) Two challenges to the idea of intellectual property. Monist 93:382-394

Błaszczyk C (2018) Propertarianistyczne teorie prawa autorskiego. C.H. Beck, Warsaw.

Błaszczyk C (2020) Lockean intellectual property refuted. Sci Polit XXXII(63):161-186

Boldrin M, Levine DK (2008) Against intellectual monopoly. Cambridge University Press, Cambridge

\footnotetext{
${ }^{9}$ Hoppe (1989:235), Kinsella (2008), Dominiak (2014), Wysocki (2014).

10 They cannot occupy the same location. Even if identical, they always have different spatial coordinates at each point in time, and may be unequivocally identified.

11 Bell (2007), Kinsella (2008), Bouillon (2009), Błaszczyk (2018:305; 2020).
} 
Bouckaert B (1990) What is property ? Harvard J Law Public Policy 13(3):775-816

Bouillon H (2009) Note on intellectual property and externalities. In: Hulsmann JG, Kinsella NS (eds) Property, freedom and society: essays in Honor of Hans-Hermann Hoppe. Ludwig von Mises Institute, Auburn, pp 149-160

Breakey H (2010) Natural intellectual property rights and the public domain. Mod Law Rev 73:208-239

Cwik B (2016) Property rights in non-rival goods. J Polit Philos 24(4):470-486

Dodd J (2000) Musical works as eternal types. Br J Aesteth 40:424-440

Dodd J (2007) Works of music: an essay in ontology. University Press, Oxford

Dominiak $€$ (2014) Anarcho-capitalism, aggression and copyright. Polit Dial 16:37-47

Drahos P (1996) A philosophy of intellectual property. Ashgate, Dartmouth

Gamrot W (2021) On type creation and ownership. Polit Dial 30:187-200

Gordon WJ (1993) A property right in self-expression: equality and individualism in the natural law of intellectual property. Yale Law J 102:1533-1609

Gordon WJ (2003) Intellectual property law. In: Cane P, Tushnet M (eds) Oxford handbook of legal studies. University Press, Oxford, pp 617-646

Himma KE (2008) The justification for intellectual property: contemporary philosophical disputes. J Am Soc Inform Sci Technol 59(7):1143-1161

Hoppe H-H (1989) A theory of socialism and capitalism. Kluwer, Boston

Hughes J (1988) The philosophy of intellectual property. Georgetown Law J 77:330-350

Kinsella NS (2008) Against intellectual property. Ludwig von Mises Institute, Auburn.

Moglen E (1999) Anarchism Triumphant: Free Software and the Death of Copyright. http://emoglen.law. columbia.edu/publications/anarchism.html [2021-04-20]

Moore A (1997) Lockean theory of intellectual property. Hamline Law Rev 21:65-108

Moore A (2003) Intellectual property, innovation and social progress: the case against incentive based arguments. Hamline Law Rev 26(3):602-630

Moore A (2012) A lockean theory of intellectual property revisited. San Diego Law Rev 49:1069-1103

Mossoff A (2012) Saving locke from Marx: the labor theory of value in intellectual property theory. Soc Philos Policy 29(2):283-317

Rand A (1986) Capitalism: the unknown ideal. Signet, New York

Risch M (2019) Abstraction, filtration and comparison in patent law. J Law Innov 1:37-64

Shaffer B (2013) A libertarian critique of intellectual property. Ludwig von Mises Institute, Auburn.

Schiffrin S (2007) Intellectual Property. In: Goodin R, Pettit P, Pogge T (eds) A companion to contemporary political philosophy. Blackwell, Oxford, pp 653-668

Wilson J (2009) Could there be a right to own intellectual property ? Law Philos 28:393-427

Wilson J (2010) Ontology and the regulation of intellectual property. Monist 93:450-463

Wiśniewski JB (2020) On the impossibility of intellectual property. Q J Aust Econ 23(1):33-45

Wysocki I (2014) The rebuttal of pro-IP arguments. Polit Dial 17:33-39

Yen AC (1990) Restoring the natural law: copyright as labor and possession. Ohio State Law J 51:517-559

Zemer L (2006) The making of a new copyright Lockean. Harvard J Law Public Policy 29(3):891-947

Publisher's Note Springer Nature remains neutral with regard to jurisdictional claims in published maps and institutional affiliations. 